\title{
Production of Recombinant Human Interleukin-11 (IL-11) in Transgenic Tobacco (Nicotiana tabacum) Plants
}

\author{
Abdorrahim Sadeghi - Majid Mahdieh - Somayeh Salimi \\ Received: 10 May 2016 / Revised: 20 June 2016 / Accepted: 20 June 2016 \\ (C) Korean Society for Plant Biotechnology
}

\begin{abstract}
Interleukin-11 (IL-11) is a cytokine that plays a key regulatory role in the immune system. Recombinant human IL-11 (rhIL-11) exerts a preventative effect against apoptotic cell death and inhibits preadipocyte differentiation. IL-11 also is used to stimulate the bone marrow to produce platelets in order to prevent low platelets that may be caused by chemotherapy. Unfortunately, the high production cost of IL-11 associated. In this study, we investigated the feasibility of transgenic plants for the cost-effective production of rhIL-11. Production of rhIL-11 proteins in whole-plant expression system will be more economical when compared to the current $E$. coli based expression system. The human rhIL-11 gene was codon optimized to maximize plant host system expression. IL-11 expression vector under the control of a constitutive cauliflower mosaic virus 35S (CaMV 35S) promoter was introduced into tobacco by Agrobacteriummediated transformation. The 5 '-leader sequence (called $\Omega$ ) of tobacco mosaic virus (TMV) as a translational enhancer was added to construct. Transgenic tobacco plants expressing various levels of rhIL-11 protein were generated. Western blotting of the stably transformed lines demonstrated accumulation of the appropriately sized rhIL-11 protein in leaves. This research demonstrated the efficacy of using tobacco as an expression system for the production of rhIL-11.
\end{abstract}

Keywords Cytokine, Recombinant human interleukin-11, Transgene expression, Transgenic plant

A. Sadeghi $\cdot$ S. Salimi

Molecular and Medicine Research Center, Department of

Biochemistry, School of Medicine, Arak University of Medical

Science, Arak, Iran

M. Mahdieh ( $\square)$

Department of Biology, Faculty of Science, Arak University,

38156-8-8138, Arak, Iran

e-mail: m-mahdiyeh@araku.ac.ir

\section{Introduction}

The need for low-cost and efficient production systems is an important factor in pharmaceutical protein production (Lienard et al. 2007). Plants have been used as recombinant protein production systems over the past decades because of low cost of production in comparison to microorganisms and especially animal cell systems. A major limitation for the production of recombinant proteins in prokaryotic systems is the lack of, or incorrect, post-translational modifications. Higher eukaryotic systems such as mammalian cells are restricted by their limited scalability and high cost of production.

Plants offer many advantages over conventional protein expression systems such as low production costs, rapid scalability, the absence of human pathogens and the ability to correctly fold and assemble complex multimeric proteins (Twyman et al. 2003). As well, plants have the ability to perform the majority of post-translational modifications needed for biological activity of such proteins.

Second, growing plants is much less expensive than raising animals for the production of proteins. Third, there are less ethical problems involved in the use of plants than the use of animal systems. However, the use of plants also carries a distinct disadvantage in that the glycosylation patterns of plants are different from those of humans (Park and Cheong 2002).

In the early stages of molecular farming, recombinant proteins were produced using transgenic tobacco plants. Tobacco is a good system in that it can generate high biomass yields.

Human IL-11 is a cytokine produced by stromal cells, such as fibroblasts, epithelial cells and osteoclasts that is biologically related to IL-6, leukemia inhibitory factor (LIF), oncostatin M (OSM), and ciliary neurotrophic factor (CNTF) (Karpovich et al. 2003).

Human IL-11 exerts a preventative effect against apoptotic cell death and inhibits preadipocyte differentiation. It is expressed 
in a wide variety of tissues, including thymus, lung, bone, connective tissue and central nervous system. IL-11 plays an important regulatory role in hematopoiesis by stimulating growth of myeloid, erythroid and megakaryocyte progenitor cells. It also regulates bone metabolism, inhibits production of pro inflammatory cytokines, and protects against gastromucosal injury. Human IL-11 cDNA encodes for a 199-amino acid precursor with a 21-amino acid hydrophobic signal peptide, which is cleaved to generate a $23 \mathrm{kDa}$ biologically active form. Human IL-11 contains no cysteine residues or potential glycosylation sites (Yang and Yin 1993).

Previous studies have demonstrated rhIL-2 production in potato tuber (Park and Cheong 2002), fruits of tomato (Cui et al. 2008) and tobacco cell culture (Magnuson et al. 1998). Also, the feasibility of transgenic plants for the production of rhIL-4 was demonstrated (Kaldi et al. 2013).

The 5 '-leader sequence (called $\Omega$ ) of tobacco mosaic virus (TMV) functions as a translational enhancer in plants. A poly (CAA) region within $\Omega$ is responsible for the translation enhancement and serves as a binding site for the heat shock protein, HSP101, which is required for the translational enhancement (Gallie et al. 1987). Genetic analysis has suggested that the translational activity of HSP101 requires eIF4G and eIF3 (Wells et al. 1998), two factors that promote the recruitment of 40 S ribosomal subunits to an mRNA.

In this study, we do codon optimization of the human IL-11 gene to match the codons of tobacco plant (Qian et al. 2012) and add $\Omega$ sequence of TMV to $5^{\prime}$ end for enhancement of protein expression in tobacco plant.

\section{Materials and methods}

Gene design and construction of plant expression vector

The mRNA sequence encoding the $\mathrm{h} / L-11$ was obtained from NCBI (accession number NM000641.3). The CDS region was selected and $\Omega$ sequence of TMV (accession number cs493972) was added to $5^{\prime}$ end of this region before start codon. Also entrokinase site and $6 \times$ His-tag sequence were added to $3^{\prime}$ end before stop codon. The Gens use tool was utilized to codon optimization of hIL-11 that would afford optimal expression of hIL-11 gene in N. tabacum. Finally flanking restriction sites (BamHI and SacI) were added to allow for cloning into a specific plant expression vector. This construct was synthesized by MWG-Biotech AG, Germany and cloned in PEXA plasmid. The designed gene sequence could be seen in the Figure 1.

This fragment was digested with the BamH1 and SacI

$$
\begin{aligned}
& \text { Bamhl site } \\
& \text { GGATCCGCCTAAGCTTATTTTACAACAATTACCAACAACAACAAACAACAAAC } \\
& \text { AACATTACAATTACATTTACAATTACCAGTCGACC } \\
& \text { Start codon } \\
& \text { ATG AAC TGT GTT TGC CGC CTG GTC CTG GTC GTG CTG AGC CTG TGG CCA } \\
& \text { GAT ACA GCT GTC GCC CCT GGG CCA CCA CCT GGC CCC CCT CGA GTT TCC } \\
& \text { CCA GAC CCT CGG GCC GAG CTG GAC AGC ACC GTG CTC CTG ACC CGC TCT } \\
& \text { CTC CTG GCG GAC ACG CGG CAG CTG GCT GCA CAG CTG AGG GAC AAA TTC } \\
& \text { CCA GCT GAC GGG GAC CAC AAC CTG GAT TCC CTG CCC ACC CTG GCC ATG } \\
& \text { AGT GCG GGG GCA CTG GGA GCT CTA CAG CTC CCA GGT GTG CTG ACA AGG } \\
& \text { CTG CGA GCG GAC CTA CTG TCC TAC CTG CGG CAC GTG CAG TGG CTG CGC } \\
& \text { CGG GCA GGT GGC TCT TCC CTG AAG ACC CTG GAG CCC GAG CTG GGC ACC } \\
& \text { CTG CAG GCC CGA CTG GAC CGG CTG CTG CGC CGG CTG CAG CTC CTG ATG } \\
& \text { TCC CGC CTG GCC CTG CCC CAG CCA CCC CCGGAC CCG CCG GCG CCC CCG } \\
& \text { CTG GCG CCC CCC TCC TCA GCC TGG GGG GGC ATC AGG GCC GCC CTC GCC } \\
& \text { ATC CTG GGG GGG CTG CAC CTG ACA CTT GAC TGG GCC GTG AGG GGA CTG } \\
& \text { CTG CTG CTG AAG ACT CGG CTG GAC GAC GAC GAC AAG CAC CAC CAC CAC } \\
& \text { CAC CAC TAA GAGCTC } \\
& \text { Stop SacI site }
\end{aligned}
$$

Fig. 1 The designed gene sequence for expression in tobacco plant. The Il-11 CDS region was selected and $\Omega$ sequence of TMV was added to $5^{\prime}$ end of this region before start codon. Also entrokinase site and $6 \times$ His-tag sequence were added to $3^{\prime}$ end before stop codon 


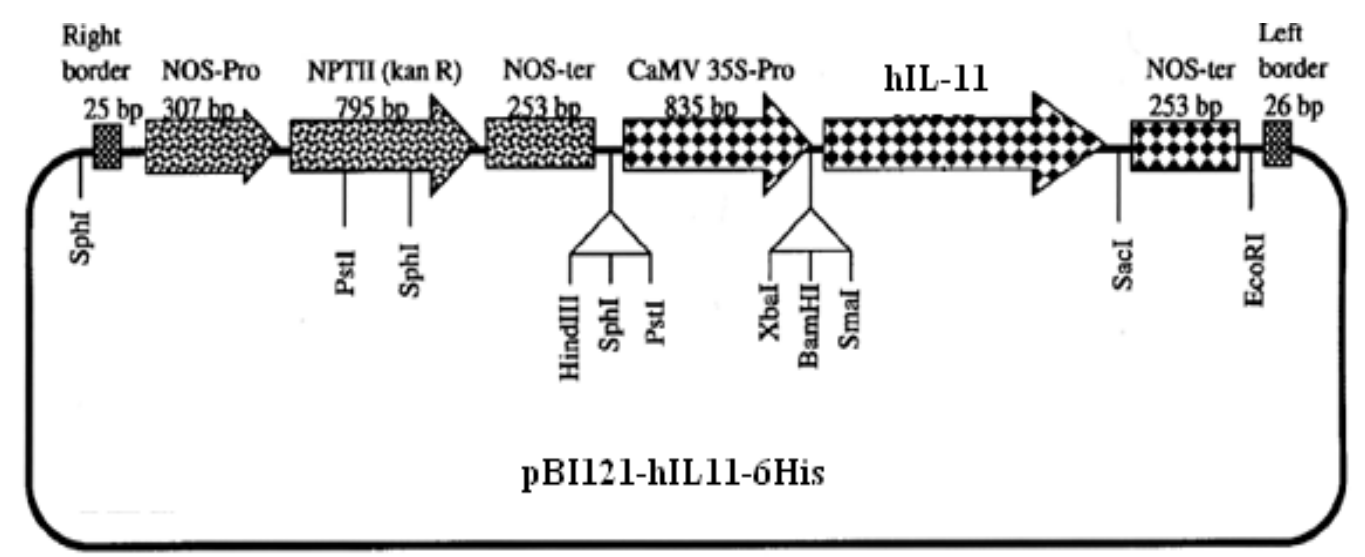

Fig. 2 Plant expression vector for the expression of hIL-11 in tobacco. The T-DNA region contains the hIL-11 protein expression cassette consisting of the cauliflower mosaic virus 35S (CaMV 35S) promoter fused to a tobacco mosaic virus (TMV) 5'-untranslated region (Omega enhancer) and nopaline synthase terminator (Nos-ter). The p35-hIL-11-6 $\times$ His construct contains a C-terminal $6 \times$ His tag

restriction enzymes and ligated into the corresponding site of plant expression vector to generate the plasmid pBI121hIL11-6×His. This vector contains the promoter from the CaMV 35S gene and nptII gene as selectable marker (Fig. 2).

Genetic transformation and regeneration of the transgenic tobacco plants

The expression vector pBI121-hIL11 was introduced into the Agrobacterium tumefaciens strain LBA4404 by freeze and thaw method (Weigel and Glazebrook 2006). Leaf disc explants from 3 week-old Nicotiana tabacum (var. Samsun) plants were transformed by the co-cultivation method described by Horsch et al. (1985). The regenerated shoots were subcultured in MS medium (Murashige and Skoog 1962) supplemented with kanamycin $(100 \mathrm{mg} / \mathrm{l})$ at $22^{\circ} \mathrm{C}$, under $120 \mu \mathrm{mol} / \mathrm{m}^{2} / \mathrm{s}$ of photon flux and a $16-\mathrm{h}$ photoperiod in a growth chamber. The putative transgenic plants were transferred into soil and cultivated in the greenhouse for further analysis.

Stable transformation was confirmed via PCR. DNA extraction was performed using a version of the CTAB method. DNA from fresh leaves was amplified using the forward primer, $5^{\prime}$ -CGCACAATCCCACTATCCTT-3', and the reverse primer, 5'-TTGCGGGACTCTAATCATAAAA-3'. PCR reactions contained $10 \mathrm{mM}$ Tris- $\mathrm{HCl}$ ( $\mathrm{pH} \mathrm{8.4),} 50 \mathrm{mM} \mathrm{KCl}, 2 \mathrm{mM} \mathrm{MgCl}_{2}$, $160 \mu \mathrm{M}$ of each dNTP, $2 \mathrm{U}$ Taq polymerase (Invitrogen), 20 ng of genomic DNA and $200 \mathrm{nM}$ of each specific primer.

PCR mixes were covered with mineral oil, and the DNA was pre-denatured at $94^{\circ} \mathrm{C}$ for $5 \mathrm{~min}$ and amplified for 35 cycles in a eppendroff DNA thermal cycler under the following conditions: $94^{\circ} \mathrm{C}$ for $1 \mathrm{~min}, 51^{\circ} \mathrm{C}$ for $1 \mathrm{~min}$ and $72^{\circ} \mathrm{C}$ for 1 min, with a final cycle at $72^{\circ} \mathrm{C}$ for $5 \mathrm{~min}$.
Western blot analysis

Fresh leaves from 4 week-old plants cultivated in the greenhouse were ground in Tris grinding buffer $(0.1 \mathrm{M}$ Tris- $\mathrm{HCl}$, $10 \mathrm{mM} \mathrm{MgCl}_{2}, 18 \%$ Sucrose, $40 \mathrm{M} 2 \mathrm{ME}$ and $\%$ (w/v) SDS) and centrifuged at $13000 \mathrm{rpm}$ for $15 \mathrm{~min}$ at $4^{\circ} \mathrm{C}$. The supernatant was collected and the total soluble protein concentration was determined by the Bradford method (Bradford 1976) using the Bio-Rad reagent with bovine serum albumin (Bio-Rad) as a standard. The proteins were separated on $12 \%$ polyacrylamide gels under reducing conditions and transferred to a PVDF membrane (Bio-Rad). The blots were blocked for $1 \mathrm{~h}$ in TBS with 3\% BSA, and incubated with commercial anti-hIL-11 antibody (PharMingen) conjugated with horseradish peroxidase (HRP) in 1:1000 dilution. After three washes in TBS-Tween 20, antibody binding was detected with 3, 3'-Diaminobenzidine (DAB).

\section{Results}

Cloning of hIL-11 gene and construction of plant expression vectors

The $h I L-11$ gene was designed from human mRNA sequence and synthesized by MWG-Biotech AG, Germany and cloned in PEXA plasmid. The expression vector was constructed in order to optimize the production yield of rhIL-11 in transgenic plants (Figure 2). A C-terminal $6 \times$ His tag was introduced into IL-11 expression vector in order to facilitate enrichment and purification of the recombinant protein using the nickel nitrilotriacetic acid (Ni-NTA) resin that can be employed for 


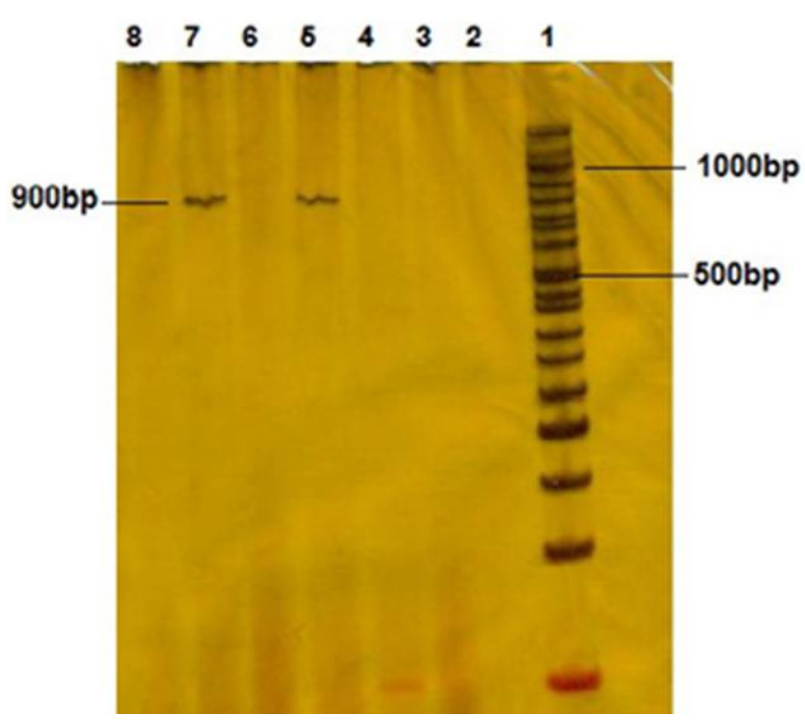

Fig. 3 RT-PCR analysis of hIL-11 mRNA expression in transgenic plants. Total RNA was extracted from the uppermost fully expanded green leaves of 6-week-old glasshouse-grown transgenic IL-11 tobacco plants or wild-type control plants and reverse-transcribed to cDNA. Lanes 2-4, representative independent transgenic tobacco lines (T1, T5, T13) carrying empty vector; Lane 5-7, representative tobacco lines (T8, T9, T17 respectively) carrying pBI121-hIL11 vector; Line 8, wild-type tobacco. Numbers on the right indicate the positions of DNA size markers

the purification of proteins tagged with six consecutive histidine residues.

Expression of rhIL-11 in transgenic tobacco plants

Transgene-positive tobacco plants were initially analyzed for IL-11 expression at the transcript level by RT-PCR. Gel analysis showed the presence of a unique band of the expected size in transgenic tobacco plants representing construct. Representative data are shown in Figure 3. No amplification product was detected in plants transformed with the control empty vector. These results indicate that the $h I L-11$ gene was actively transcribed. Transgenic lines expressing the highest levels of hIL-11 messenger RNA (mRNA) were further analyzed for hIL-11 protein production by Western blot using a rabbit anti-histag monoclonal antibody. Variable levels of rhIL-11 expression were seen in leaf extracts from individual transgenic tobacco lines.

As shown in Figure 4, the rhIL-11 expressed from transgenic tobacco plants representing pBI121-hIL11 was seen as a single band on Western blots, with the molecular mass being approximately $23 \mathrm{kDa}$. Compared with control standard rhIL-11 (lane 1), the plant-expressed rhIL-11 had a lower mobility, which is the result of the addition of the $6 \times$ His tag sequence at its C-terminus.

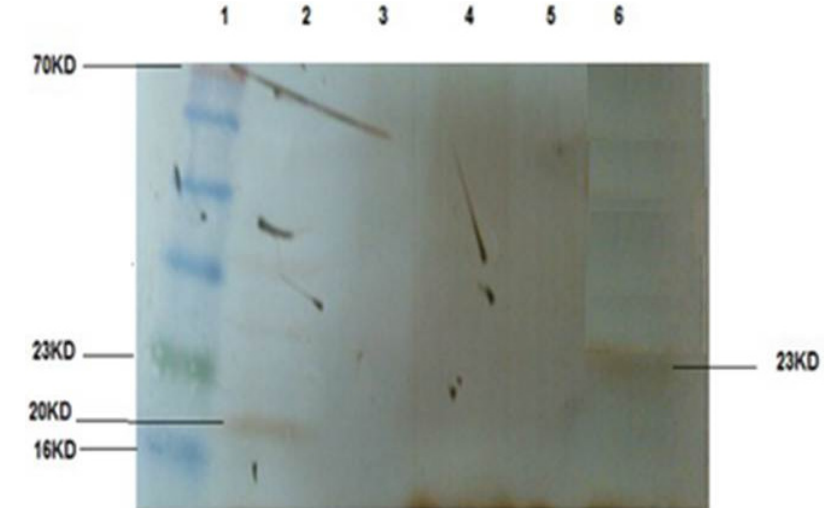

Fig. 4 Western blot analysis of hIL-11 protein expression in transgenic tobacco plants. Total protein extracts (40 $\mu \mathrm{g} / \mathrm{lane})$ from transgenic tobacco leaf tissue were fractionated by SDS-PAGE, blotted on to poly (vinylidene difluoride) (PVDF) membrane and probed with an anti-hIL-11 antibody. Lane 1, Molecular weight marker (kDa); Lane 2, standard rhIL-11 (PharMingen); lanes 3, 4 , representative independent transgenic tobacco lines (T1, T5) carrying empty vector; lane 5, wild-type tobacco and lane 6 , one representative tobacco line (T8) carrying pBI121-hIL11 vector

\section{Discussion}

In the present study, transgenic plants were evaluated for their potential as an alternative economic source for rhIL-11. For this purpose, transgenic tobacco plants carrying hIL-11 construct were generated. As rhIL-11 protein was readily detected in transgenic tobacco plants carrying construct, this suggests that chimeric hIL-11 gene is suitable for expression in transgenic tobacco plants as a model system.

Recently, using plants for the synthesis of recombinant proteins in comparison to traditional microbial and mammalian production systems has received a great deal of attention because of advantages in economy, scalability and safety.

Plant expression systems are believed to be even better than microbes in terms of cost, protein complexity, storage and distribution. Some added advantage of plant systems are glycosylation and targeting, compartmentalization and natural storage stability in certain organs (Park and Cheong 2002).

There was notable variability in the expression levels of rhIL-11 between the individual transgenic lines representing the same construct (Figure 4). Presumably, such variation can be attributed to 'position effects', chromosomal differences between sites of integration that influence gene expression (Hobbs et al. 1990).

The unpredictable silencing or variable expression of transgenes is a ubiquitous phenomenon. Transgenes are susceptible to silencing in all plant species studied, including green algae (Cerutti et al. 1997).

Position effects, which refer to repressive influences, exerted 
on transgenes by flanking plant DNA and/or an unfavorable chromosomal location. This type of silencing presumably reflects the epigenetic state of neighboring host sequences or the relative tolerance of particular chromosome regions to invasion by alien DNA.

A separate category of silencing resulting from interactions among multiple copies of transgenes and related endogenous genes involves homology-based mechanisms that act at either the transcriptional or post-transcriptional level (Meyer and Saedler, 1996). Transcriptional silencing is associated with meiotically heritable epigenetic modifications (often, but not always, cytosine methylation). This phenomenon likely can be resulted in missing protein band of line T17 in western blot (Figure 3).

The size difference shown on Western blot (Figure 4) between the plant-derived rhIL-11 and the recombinant standard may be attributed to the insertion of the $6 \times$ His tag and entrokinase sequences in plant rhIL-11, as it was produced as a fusion protein.

The addition of the $6 \times$ His to IL- 11 simplify the purification procedure of the recombinant protein from the crude plant extract and thus allow rapid biochemical and functional characterization of the recombinant protein.

Moreover, as we have demonstrated in the present study, together with previous work from other groups (Gallie et al. 1987), the use of the tobacco mosaic virus (TMV) 5 'omega leader sequence enhances the expression of foreign gene transcripts in plants. Creager et al. (1999) reported the commercial use of the TMV omega leader sequence for the transgenic expression of therapeutic human enzymes from field-grown tobacco plants. The translational enhancement of both the TEV and TMV omega leader sequences for the expression of the human calcitonin gene in independent transgenic potato plants showed that the TMV omega element provided an increase of between two- and three-fold of that which was achieved by the TEV leader sequence (Ofoghi et al. 2005).

\section{Conclusions}

Our results suggested that plants are a suitable system for the expression of hIL-11 and may aid basic study for the high production of hIL-11 in plants. This is the first report on the production of functional rhIL-11 using transgenic plants. More studies are needed to optimize protein production in plants (by nucleus or chloroplast transformation) and extraction/ purification methods which have a substantial influence on final yields. The novel and challenging task in molecular farming is the combination of genetic engineering, protein extraction, and development of adequate manufacturing and processing technology.

\section{References}

Bradford MM (1976) A rapid and sensitive method for the quantitation of microgram quantities of protein utilizing the principle of protein-dye binding. Anal Biochem 72:248-254

Cerutti H, Johnson A, Gillham N, Boynton J (1997) Epigenetic silencing of a foreign gene in nuclear transformants of Chlamydomonas. Plant Cell 9:925-945.

Creager ANH, Scholthof K-BG, Citovsky V, Scholthof H (1999) Tobacco mosaic virus: pioneering research for a century. Plant Cell 11:301-308

Cui J, Yu L, Chen S, Liu S, Fu C (2008) Expression of Recombinant Human Interleukin-2 in Tomato Fruits. J Biotech 136:S235-S235

Gallie DR, Sleat DE, Watts JW, Turner PC, Wilson TMA (1987). The 5'-leader sequence of tobacco mosaic virus RNA enhances the expression of foreign gene transcripts in vitro and in vivo. Nucleic Acids Res 15:3257-3273

Hobbs SLA, Kpodar P, Delong CMO (1990) The effect of T-DNA copy number, position and methylation on reporter gene expression in tobacco transformants. Plant Mol Biol 15: 851864

Horsch RB, Fry JE, Hoffmann NL, Eichholtz D, Rogers SG, Fraley RT (1985) A simple and general method for transferring genes into plants. Science 227:1229-1231

Kaldi A, Ahmad A, Reid A, McGarvey B, Brandle J, Ma S, Jevnikar A, Kohalmi SE, Menassa R (2013) High-level production of human interleukin-10 fusions in tobacco cell suspension cultures. Plant Biotech J 11:535-545

Karpovich N, Chobotova K, Carver J, Heath JK, Barlowand, DH, Mardon, HJ (2003) Expression and function of interleukin-11 and its receptor $\mathrm{a}$ in the human endometrium. Mol Hum Reprod 9:75-80

Lienard D, Sourrouille C, Gomord V, Faye L (2007) Farming and transgenic plants. Biotechnol Annu Rev 13:115-147

Magnuson NS, Linzmaier PM, Reeves R, An G, Hayglass K, Lee JM(1998) Secretion of biologically active human interleukin-2 and interleukin-4 from genetically modified tobacco cells in suspension culture. Protein Expr Purif 13:45-52

Meyer P, Saedler H (1996) Homology-dependent gene silencing in plants. Annu Rev Plant Physiol Plant Mol Biol 47:23-48

Murashige T, Skoog F (1962) A revised medium for rapid growth and bioassays with tobacco tissue cultures. Physiol Plant 15:473-497

Ofoghi H, Moazami N, Ivanov I (2005) Comparison of tobacco etch virus and tobacco mosaic virus enhances for expression of human calcitonin gene in transgenic potato plant. Key Engin Mat 277:7-11

Park Y, Cheong H (2002) Expression and production of recombinant human interleukin-2 in potato plants. Protein Expr Purif 25: $160-165$

Qian W, Yang JR, Pearson NM, Maclean C, Zhang J (2012) 
Balanced codon usage optimizes eukaryotic translational efficiency. PLoS Genet 8:e1002603

Twyman RM, Stoger E, Schillberg S, Christou P, Fischer R (2003) Molecular farming in plants: host systems and expression technology. Trends Biotechnol 21:570-578

Weigel D, Glazebrook J (2006) Transformation of Agrobacterium using the freeze-thaw method. Cold Spring Harb Protoc. doi:10.1101/pdb.prot4666

Wells DR, Tanguay RL, Le H, Gallie DR (1998) HSP101 functions as a specific translational regulatory protein whose activity is regulated by nutrient status. Genes Dev 12:3236-3251

Yang YC, Yin T (1993) Interleukin-11 and its receptor. BioFactors 4:15-21 